\title{
Membrane Potential Depolarization Alters Calcium Flux and Phosphate Signaling During Osteogenic Differentiation of Human Mesenchymal Stem Cells
}

\author{
Sarah Sundelacruz, PhD, ${ }^{1}$ Amy Thurber Moody, PhD, ${ }^{1}$ Michael Levin, $\mathrm{PhD},{ }^{2}$ and David L. Kaplan, $\mathrm{PhD}^{1}$
}

\begin{abstract}
Background: Membrane potential $\left(\mathrm{V}_{\text {mem }}\right)$ changes accompany important events in embryonic development and organ regeneration. Recent studies have pointed to its function as a potent regulator of cell proliferation, differentiation, migration, and tissue regeneration. We have previously reported that $\mathrm{V}_{\text {mem }}$ depolarization and hyperpolarization control the osteogenic (OS) differentiation potential of human mesenchymal stem cells (hMSCs).

Materials and Methods: In this study, we sought to understand the mechanism(s) underlying voltage regulation of hMSC differentiation. We investigated the role of calcium and phosphate ion flux in the depolarization response of OS-differentiating hMSCs, as these ions are the two major inorganic components of the bone mineral matrix and are indicative of mature osteoblast function.

Results: Our results suggest that inorganic phosphate levels play a larger role than calcium flux in mediating hMSC response to depolarization and that the expression of stanniocalcin 1 (STC1), a protein that regulates calcium and phosphate homeostasis in osteoblasts, is functionally required for the depolarization response during the early stages of differentiation.

Conclusion: Depolarization alters hMSC differentiation through a phosphate signaling pathway involving STC1. This study enriches our mechanistic understanding of hMSC response to endogenous voltage cues.
\end{abstract}

Keywords: stem cells, calcium, phosphate, membrane potential

\section{Introduction}

$\mathbf{R}$ ECENT STUDIES EXAMINING the role of bioelectric signaling in stem cell function have demonstrated a functional role for endogenous electrophysiological signals in stem cell differentiation. ${ }^{1}$ For example, in human myoblasts, differentiation requires and may be triggered by membrane potential $\left(\mathrm{V}_{\mathrm{mem}}\right)$ hyperpolarization. ${ }^{2-4}$ Hyperpolarization occurs through the Kir2.1 channel and results in $\mathrm{Ca}^{2+}$ influx, calcineurin $(\mathrm{Cn})$ activation, and expression of myogenic transcription factors, resulting in myocyte fusion. ${ }^{2,5,6}$ Hyperpolarization also stimulates cardiomyocyte progenitor cell differentiation into functional cardiomyocytes and cardiogenic differentiation of embryonic stem cells (ESCs), mediated by $\mathrm{Ca}^{2+}$ and smalland intermediate-conductance calcium-activated $\mathrm{K}^{+}$channels (SKCa), respectively. ${ }^{7,8}$ In mouse cerebellar granule cells, $\mathrm{V}_{\text {mem }}$ depolarization induces a gene expression pattern correlated to their developmental expression pattern, potentially operating through a signaling pathway involving $\mathrm{Ca}^{2+}, \mathrm{Cn}$, and $\mathrm{Ca}^{2+}$-calmodulin (CaM)-dependent protein kinase. 9 These studies demonstrate that modulation of ion flux and ion channel activity produces $\mathrm{V}_{\text {mem }}$ changes that can induce myogenic and neurogenic differentiation, identifying voltage signaling as a functional regulatory mechanism.

Beyond these neural- and muscle-related cells, both of which are excitable cell types, the differentiation of nonexcitable cell types may also be regulated by $\mathrm{V}_{\text {mem }}$ signaling. For example, in mouse ESCs, depolarization by blockade of voltage-gated $\mathrm{K}^{+}$ (Kv) channels results in not only decreased proliferation but also loss of pluripotency, as measured by loss of Oct-4, Sox-2, and Nanog expression, and an increase in expression of early germ layer markers, particularly of the mesendoderm and trophectoderm. Since Kv channel activity is largely responsible for setting the resting $\mathrm{V}_{\text {mem }}$ in these cells, $\mathrm{Kv}$ activity may function as a switch between the decision to self-renew or to differentiate. ${ }^{10}$ Our previous studies of $\mathrm{V}_{\text {mem }}$ modulation in human mesenchymal stem cells (hMSCs) revealed a role for voltage in regulation of hMSC differentiation. We demonstrated that $\mathrm{V}_{\text {mem }}$ hyperpolarization accompanies and is required for osteogenic (OS) and adipogenic (AD) differentiation. HMSCs respond to $\mathrm{V}_{\text {mem }}$ modulation in the depolarized and hyperpolarized direction by suppressing or augmenting OS differentiation, respectively. Cells therefore exhibit bidirectional sensitivity to $\mathrm{V}_{\text {mem }}$ changes. Together, these results support a

\footnotetext{
${ }^{1}$ Department of Biomedical Engineering, Tufts University, Medford, Massachusetts.

${ }^{2}$ Allen Discovery Center at Tufts University, Department of Biology, Medford, Massachusetts.
} 
growing body of literature reporting a role for $\mathrm{V}_{\text {mem }}$ in cell proliferation, differentiation, migration, wound healing, and tissue regeneration. In addition to clear implications for the bioelectric regulation of stem cells in bioengineering contexts, manipulation of $\mathrm{V}_{\text {mem }}$ represents a promising and tractable approach to triggering complex regenerative events involving both stem and somatic precursors. ${ }^{11,12}$

Despite the emerging evidence of bioelectric regulation of stem cells, there remains a significant knowledge gap regarding the mechanisms by which voltage changes at the cell membrane lead to specific intracellular responses such as suppressed or augmented differentiation. Several $\mathrm{V}_{\text {mem}^{-}}$ sensing mechanisms are candidates for mediating these responses, including $\mathrm{Ca}^{2+}$ signaling, integrin-linked signaling, voltage-sensing phosphatases, and voltage-dependent changes in the transport of intracellular signaling molecules. ${ }^{13-25} \mathrm{Ca}^{2+}$ signaling is by far the most well-studied of these mechanisms, and its critical role in cell and organismal development has been reviewed in depth elsewhere. ${ }^{22-25}$ Importantly, calciumdependent transduction of electrical activity is most often studied in the context of rapid spiking (action potentials) in the nervous system, with very little information available on the dynamics of resulting calcium movements following longterm $\mathrm{V}_{\text {mem }}$ changes relevant to developmental bioelectricity. In this study, we highlight that $\mathrm{Ca}^{2+}$ signaling has been implicated specifically in the aforementioned studies that suggest an instructive role for $\mathrm{V}_{\text {mem }}$ in cell differentiation. ${ }^{2-9} \mathrm{Ca}^{2+}$ signaling is also of particular relevance to hMSC research, as previous studies have demonstrated the importance of $\mathrm{Ca}^{2+}$ signaling in osteoblast differentiation. ${ }^{26,27} \mathrm{We}$ therefore investigated whether $\mathrm{Ca}^{2+}$ flux is altered by $\mathrm{V}_{\text {mem }}$ depolarization in hMSCs undergoing OS differentiation, and whether this flux plays a significant role in the depolarization response of hMSCs.

Furthermore, we investigated the role of another important ion, inorganic phosphate $(\mathrm{Pi})$, in the voltage response of hMSCs. Pi has a central role in vital cell processes, including cell metabolism and intracellular signaling. ${ }^{28}$ Of relevance to hMSCs, $\mathrm{Pi}$ is a major component of bone mineral and acts as a signaling molecule during osteoblast differentiation. ${ }^{28-31}$ While the transmembrane difference in anionic $\mathrm{Pi}$ concentrations does not significantly impact resting $\mathrm{V}_{\text {mem }}$ and is not directly responsive to $\mathrm{V}_{\text {mem }}$ changes, intracellular Pi levels may change with $\mathrm{V}_{\text {mem }}$ levels as a result of cotransport with other ions such as $\mathrm{Na}^{+}$, for example, through the type III $\mathrm{Na}^{+}-$ dependent phosphate transporter PiT1 (SLC20A1). ${ }^{32,33}$ In this study, we examined whether Pi signaling may be modulated to alter hMSC response to $\mathrm{V}_{\text {mem }}$ depolarization, and we discovered a role for the calcium- and phosphate-regulating hormone stanniocalcin 1 (STC1) in this response. This study identifies a potential molecular mechanism through which hMSCs respond to electrophysiological signals and advances our understanding of how bioelectric signaling acts as an endogenous regulator of stem cell differentiation.

\section{Experimental Procedures}

\section{Cell culture}

Bone marrow aspirate from a 25-year-old healthy male donor was obtained through Lonza's Research Bone Marrow Donor Program (Hopkinton, MA) following approved guidelines of informed consent. HMSCs were isolated from the aspirate based on their adherence to tissue-culture plastic, as reported previously. ${ }^{34}$ Briefly, aspirate was plated at a density of $10 \mu \mathrm{L}$ aspirate per $\mathrm{cm}^{2}$ in tissue-culture treated flasks and cultured in a humidified incubator maintained at $37^{\circ} \mathrm{C}$ and $5 \% \mathrm{CO}_{2}$. Bone marrow aspirate was cultured in control medium (consisting of Dulbecco's modified Eagle's medium with $10 \%$ fetal bovine serum [FBS], penicillin [100 U/mL], streptomycin [100 $\mu \mathrm{g} /$ $\mathrm{mL}$ ], and $0.1 \mathrm{mM}$ nonessential amino acids) supplemented with basic fibroblast growth factor (bFGF) at $1 \mathrm{ng} / \mathrm{mL}$ (Invitrogen, Carlsbad, CA). Hematopoietic cells, which remained in suspension, were removed after $\sim 5$ days of culture. Adherent hMSCs were cultured until near confluence, then trypsinized and frozen in liquid $\mathrm{N}_{2}$. For subsequent experiments, hMSCs were expanded in control medium with $1 \mathrm{ng} / \mathrm{mL} \mathrm{bFGF}$ at $37^{\circ} \mathrm{C}$, $5 \% \mathrm{CO}_{2}$, and $5 \% \mathrm{O}_{2}$. For OS differentiation, cells were cultured at $37^{\circ} \mathrm{C}$ and $5 \% \mathrm{CO}_{2}$ under normoxic conditions in OS medium. OS medium consisted of $\alpha$-MEM supplemented with $10 \%$ FBS, penicillin $(100 \mathrm{U} / \mathrm{mL})$, streptomycin $(100 \mu \mathrm{g} / \mathrm{mL}), 10 \mathrm{mM} \beta$ glycerophosphate, $0.05 \mathrm{mM}$ L-ascorbic acid-2-phosphate, and $100 \mathrm{nM}$ dexamethasone (Sigma-Aldrich, St. Louis, MO). Undifferentiated hMSCs were maintained in control medium.

Calcium flux was blocked by supplementing OS medium with $500 \mu \mathrm{M}$ lanthanum chloride $\left(\mathrm{LaCl}_{3}\right)$, a nonspecific calcium channel blocker. ATP was depleted from the culture medium by the addition of hexokinase $(5 \mathrm{U} / \mathrm{mL})$, an enzyme that phosphorylates glucose by consuming ATP. ${ }^{35-38} \mathrm{P} 2 \mathrm{X}$ and P2Y purinergic receptor activity was probed with several pharmacological antagonists of purinergic receptors. Pyridoxalphosphate6-azophenyl-2',4'-disulfonic acid tetrasodium salt (PPADS), a nonspecific $\mathrm{P} 2$ blocker, was added to OS medium at a concentration of $10-30 \mu \mathrm{M}$. 2',3'-O-(2,4,6-Trinitrophenyl)adenosine$5^{\prime}$-triphosphate tetra(triethylammonium) salt (TNP-ATP), a specific P2X blocker, was added to OS medium at a concentration of $0.1-1 \mu \mathrm{M}^{37,38}$; Pannexin-1 channel blocker carbenoxolone (CBX) was also administered at $10 \mu \mathrm{M}$ to block ATP release from hemi-gap-junctional channels. Cells were cultured under elevated phosphate conditions by supplementing OS medium with $5 \mathrm{mM}$ sodium phosphate. Phosphate transport was blocked by supplementing the medium with foscarnet (fosc), an inhibitor of phosphate uptake. ${ }^{30,39}$ All chemicals were from Sigma-Aldrich.

\section{$V_{\text {mem }}$ depolarization}

Depolarization was achieved by elevating the concentration of extracellular $\mathrm{K}^{+}$in OS medium through addition of potassium gluconate at a concentration of $40 \mathrm{mM}$. Normally, the extracellular $\left[\mathrm{K}^{+}\right]$is significantly lower than the intracellular $\left[\mathrm{K}^{+}\right]$, resulting in a small $\left[\mathrm{K}^{+}\right]_{\text {out }} /\left[\mathrm{K}^{+}\right]_{\text {in }}$ ratio. By elevating the extracellular $\left[\mathrm{K}^{+}\right]$, the ratio $\left[\mathrm{K}^{+}\right]_{\text {out }} /\left[\mathrm{K}^{+}\right]_{\text {in }}$ increases. The Goldman-Hodgkin-Katz equation, which expresses $\mathrm{V}_{\text {mem }}$ in terms of extracellular and intracellular ion compositions and ion permeabilities, predicts that such a change in $\left[\mathrm{K}^{+}\right]_{\text {out }} /\left[\mathrm{K}^{+}\right]_{\text {in }}$ would result in an increased, or depolarized, $\mathrm{V}_{\text {mem. }} \cdot{ }^{40,41}$ We have previously verified by sharp microelectrode recordings and voltage-sensitive dyes that addition of potassium gluconate causes depolarization. ${ }^{34}$

\section{$\mathrm{Ca}^{2+}$ flux imaging}

To visualize $\mathrm{Ca}^{2+}$ dynamics during depolarization, $\mathrm{Ca}^{2+}$ flux was monitored by fluorescence imaging using the $\mathrm{Ca}^{2+}$ sensitive dye Fluo-4 (Molecular Probes, Inc., Eugene, OR). hMSCs were cultured on glass-bottom dishes, incubated in 
$10 \mu \mathrm{M}$ Fluo-4 for $30 \mathrm{~min}$, washed in Hank's Balanced Salt solution, and imaged on a confocal microscope with an inverted DM IRE2 stand (Wetzlar, Germany) and a Leica PL APO 63x (NA 1.2) water-immersion objective. Fluo-4 was excited with a $488 \mathrm{~nm}$ ArKr laser; images were collected at $530 \pm 5 \mathrm{~nm}$ by a nondescanned photomultiplier tube controlled by Leica Confocal Software. A double dichroic filter was used to eliminate $488 \mathrm{~nm}$ excitation light. Time lapse series were taken at $10 \mathrm{~s}$ intervals over a period of $20-40 \mathrm{~min}$ to capture $\mathrm{Ca}^{2+}$ oscillations. After monitoring baseline oscillations, hMSCs were depolarized by addition of $40 \mathrm{mM}$ K-gluconate and then imaged for an additional 20-60 min. ImageJ software was used for basic image processing, including drawing of regions of interest around individual cells and calculating average pixel intensity per cell per time slice. Fluorescence intensity was normalized to minimum intensity values and was monitored over time for each cell. Thus, each normalized intensity trace should have a baseline value at $\sim 1$. However, the data series were plotted with an offset for better visualization of individual cell traces. Peak analysis was performed to obtain parameters such as percentage of cells with $\mathrm{Ca}^{2+}$ spikes, frequency of $\mathrm{Ca}^{2+}$ spikes per cell, and peak duration (OriginPro).

\section{$\operatorname{siRNA}$}

STC1 expression in hMSCs was knocked down using siRNA. Lipofectamine RNAiMAX was used to transfect STC1-specific Silencer Select siRNA (Invitrogen). siRNA against glyceraldehyde 3-phosphate dehydrogenase (GAPDH) was used as a positive control for transfection. Negative Control siRNA \#1 (Invitrogen) was used as a negative control against nonspecific siRNA effects, and a mock transfection using vehicle only (water) was performed as a transfection control. Cells were incubated for $72 \mathrm{~h}$ with siRNA and Lipofectamine in OptiMEM medium (Invitrogen) without FBS. Lipofectamine and siRNA were removed at $72 \mathrm{~h}$, and transfected cells were used immediately for depolarization experiments. Gene knockdown was verified at $24 \mathrm{~h}$ post-transfection and on day 7 of depolarization experiments.

\section{Quantitative polymerase chain reaction}

Quantitative polymerase chain reaction (qPCR) was performed to assess gene expression. mRNA was isolated by phenol-chloroform extraction. Briefly, cells were harvested in TRIzol reagent and mixed with chloroform. After centrifugation, the aqueous phase was collected and mixed with $70 \%$ ethanol to precipitate the mRNA. mRNA was further purified using RNeasy mini spin columns (Qiagen) and quantified using a NanoDrop 2000. Reverse transcription was performed using the High-Capacity cDNA Archive Kit following the manufacturer's instructions (Applied Biosystems, Foster City, CA). Gene transcripts were amplified using the Brilliant III Ultra-Fast qPCR Master Mix (Agilent) and quantified with a Stratagene Mx3000P qPCR instrument (Agilent). TaqMan Gene Expression Assay Kits were used for gene-specific primers and probes. Integrin-binding sialoprotein $(I B S P)$ and alkaline phosphatase gene $(A L P L)$ are transcripts commonly upregulated during OS differentiation and were used as indicators of differentiation in this study. Expression levels were normalized to the housekeeping gene GAPDH and reported as fold-change relative to an untreated undifferentiated group.

\section{DNA quantification}

DNA quantification was performed as a surrogate measurement for total cell number per sample. Cells were lysed in $0.2 \% \mathrm{v} / \mathrm{v}$ Triton $\mathrm{X}-100$ in $5 \mathrm{mM} \mathrm{MgCl}_{2}$ and centrifuged at $16,000 \mathrm{~g}$ at $4^{\circ} \mathrm{C}$ for $10 \mathrm{~min}$. Supernatants were collected and diluted in TE buffer before being mixed with PicoGreen dsDNA assay reagent (Invitrogen). Fluorescence measurements were taken at excitation and emission wavelengths of 480 and $520 \mathrm{~nm}$, respectively.

\section{Total calcium quantification}

Total calcium levels were quantified using the Stanbio CPC LiquiColor Kit (Stanbio Laboratory) according to the manufacturer's instructions. OS samples were collected in $5 \%$ trichloroacetic acid, cleared of debris by centrifuging at $16,000 \mathrm{~g}$ for $5 \mathrm{~min}$ at room temperature, and incubated with the working assay reagent for 5 min. Sample absorbance was measured at $575 \mathrm{~nm}$.

\section{Alkaline phosphatase and Alizarin Red S staining}

Alkaline phosphatase protein (ALP) activity and matrix mineralization, two markers of OS differentiation, were evaluated by an ALP staining assay and an Alizarin Red S staining assay, respectively. OS samples were fixed with $10 \%$ formalin for $1 \mathrm{~h}$, washed twice in PBS, and stained for ALP using the Leukocyte ALP Assay Kit (Sigma). After staining, samples were washed in PBS and then imaged in PBS with an inverted microscope (Axiovert S100, Carl Zeiss, Inc.) equipped with Zeiss A-Plan 10x (NA 0.25) and LD A-Plan 32x (0.40) objectives. Images captured by a Sony Exwave HAD CCD camera were acquired using ImageJ software $(\mathrm{NIH})$. After imaging, samples were stained with Alizarin Red S to visualize calcium deposits. Samples were incubated

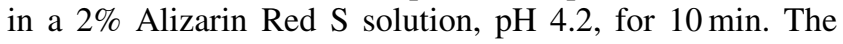
staining solution was removed, and samples were washed with PBS four times and imaged as above.

\section{Phosphate quantification}

Levels of intracellular Pi were quantified using the Malachite Green Phosphate Assay Kit (Cayman Chemical Company) according to the manufacturer's instructions.

\section{Statistics}

Data are reported as mean \pm standard deviation. For pairwise comparisons, a Student's $t$-test was used. For multiple comparisons, a one-way ANOVA was performed, followed by the Tukey-Kramer post hoc test. Differences were considered significant if $p<0.05$.

\section{Results \\ $\mathrm{Ca}^{2+}$ flux dynamics are altered in depolarized cells}

Endogenous $\mathrm{Ca}^{2+}$ flux was visualized by staining hMSCs with Fluo4, a $\mathrm{Ca}^{2+}$-sensitive fluorescent dye. In a nondepolarized cell population, $19 \%$ of cells exhibited spontaneous $\mathrm{Ca}^{2+}$ oscillations and an average of 1 peak per firing cell over an observation period of $20 \mathrm{~min}$. The oscillations occurred with a frequency of 0.25 peaks $/ \mathrm{min}$ and an average peak duration of $0.5 \mathrm{~min}$ at half maximum (Fig. 1A). After 

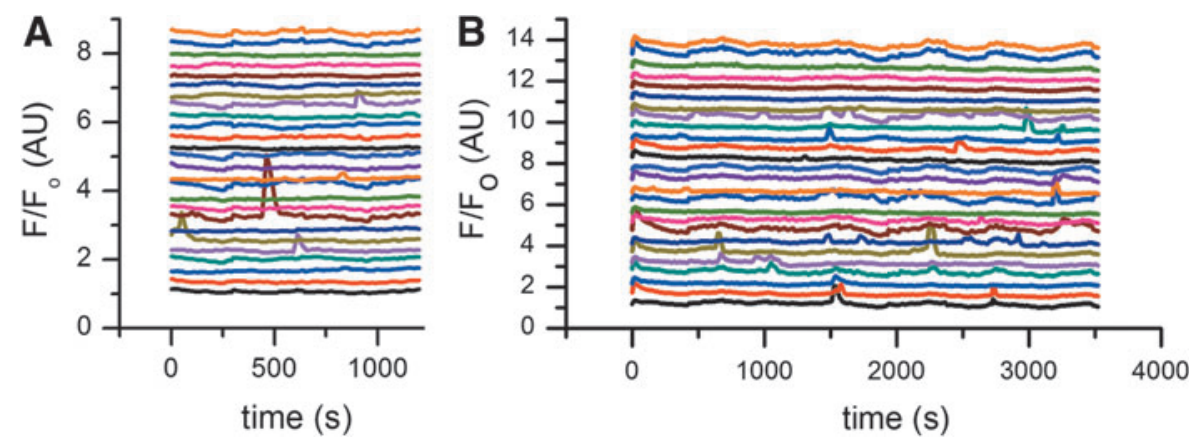

FIG. 1. $\mathrm{Ca}^{2+}$ flux dynamics is altered in depolarized cells. hMSCs were labeled with Fluo-4, a Ca ${ }^{2+}$ sensitive dye, to monitor $\mathrm{Ca}^{2+}$ oscillations. Fluorescence intensity values over time (normalized to minimum intensity values) were calculated for each cell. $\mathrm{Ca}^{2+}$ oscillations were monitored before and after depolarization treatment with $40 \mathrm{mM} \mathrm{K}^{+}$, and representative normalized intensity traces are shown in $(\mathbf{A}, \mathbf{B})$, respectively. Plots of the intensity traces were offset for better visualization. hMSC, human mesenchymal stem cell.
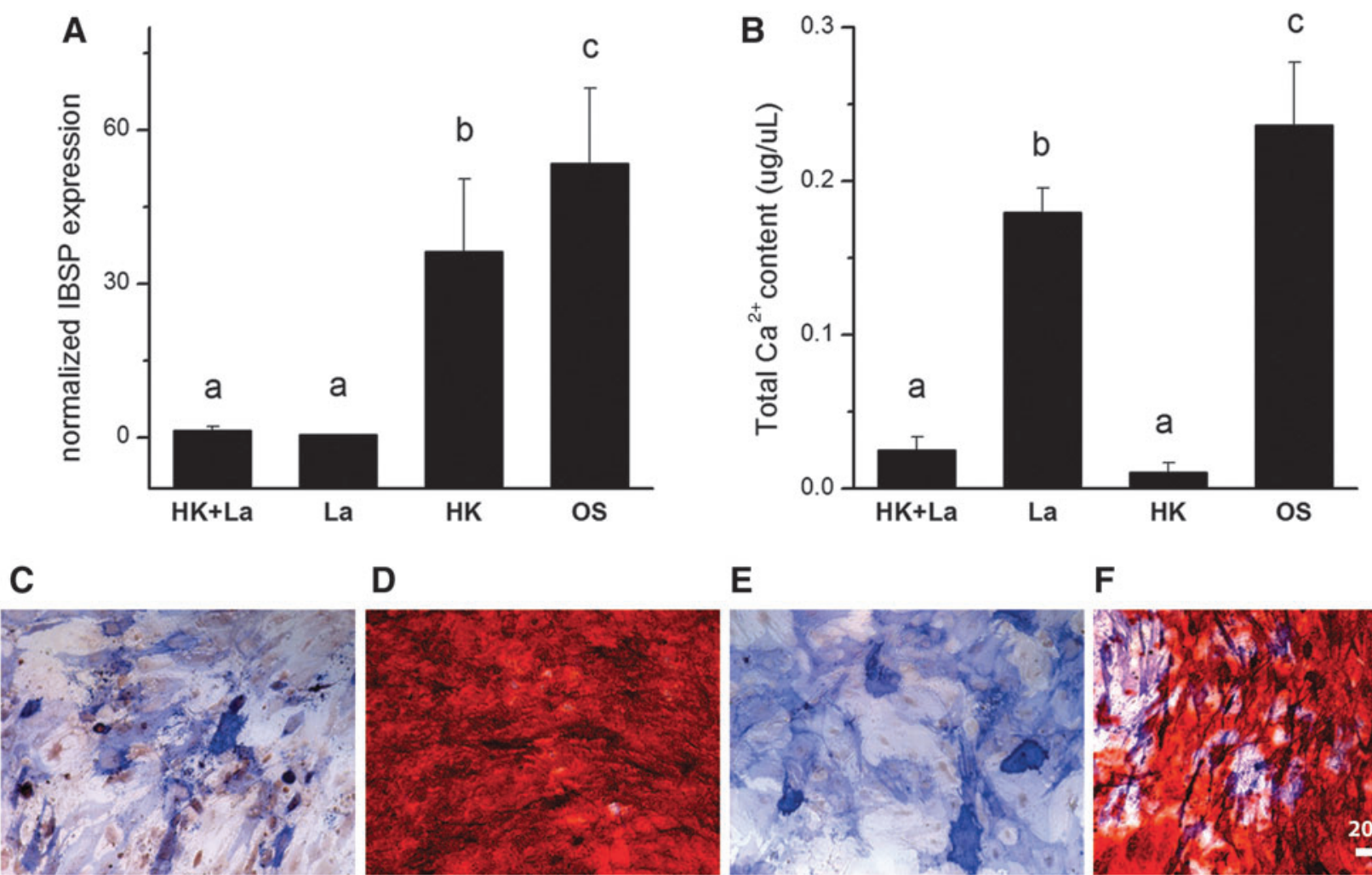

D

E

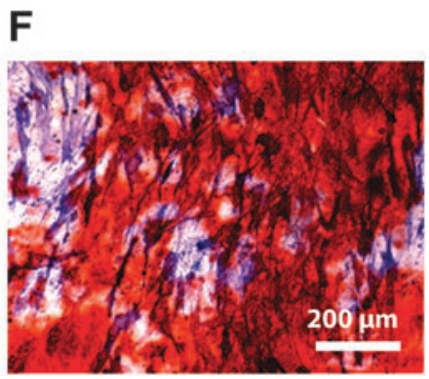

FIG. 2. Calcium block does not rescue OS differentiation in depolarized hMSCs. hMSCs were treated with $\mathrm{LaCl}_{3}$ to block calcium flux during OS differentiation. (A) IBSP gene expression was quantified by qPCR after 7 days of hMSC culture in OS medium with $40 \mathrm{mM} \mathrm{K}{ }^{+}(\mathrm{HK})$ and/or $500 \mu \mathrm{M} \mathrm{LaCl}_{3}(\mathrm{La})$. Data points are mean normalized expression \pm standard deviation, $n=3$. Different letters over the bars represent statistically different groups as determined by one-way ANOVA and the Tukey-Kramer post hoc test $(p<0.05)$. Groups (a), (b), and (c) were statistically different from one another, but the samples within group (a) were not statistically different from one another. (B) Total calcium content was quantified after 21 days of hMSC culture under the same conditions. Data points represent mean calcium concentration $(\mu \mathrm{g} / \mathrm{mL}) \pm \mathrm{standard}$ deviation, $n=6$. Different letters over the bars represent statistically different groups as determined by one-way ANOVA and the Tukey-Kramer post hoc test $(p<0.05)$. Groups $(\mathbf{a}),(\mathbf{b})$, and (c) were statistically different from one another, but the samples within group (a) were not statistically different from one another. (C-F) Representative images of cells stained at day 21 for ALP (blue) and calcified mineral (Alizarin Red S). Cells were grown in media supplemented with La+HK (C), La (D), HK (E), or in normal OS medium (F). Scale bar $=200 \mu \mathrm{m}$. HK, high $\mathrm{K}^{+} ; I B S P$, integrin-binding sialoprotein; LaCl ${ }_{3}$, lanthanum chloride; OS, osteogenic. 
stimulation with $40 \mathrm{mM} \mathrm{K}^{+}$, the number of oscillating cells remained the same over an observation period of $20 \mathrm{~min}$. However, the average number of peaks per firing cell increased 1.8-fold to 1.8 peaks, the overall frequency of oscillations increased 1.8 -fold to $0.45 \mathrm{peaks} / \mathrm{min}$, and the average peak duration at half maximum increased 2.0-fold to 1.0 min (Fig. 1B). Extended monitoring of $\mathrm{Ca}^{2+}$ oscillations out to $\sim 1 \mathrm{~h}$ after the initial stimulation with $40 \mathrm{mM} \mathrm{K}^{+}$revealed that compared to predepolarized conditions, the number of oscillating cells increased threefold to $56 \%$, the average number of peaks per firing cell increased 2.6-fold to 2.6 peaks, and the overall frequency of oscillations increased 2.7-fold to 0.66 peaks/min (Fig. 1B). We conclude that hMSC depolarization by high $\mathrm{K}^{+}$results in an increase in the number of cells exhibiting $\mathrm{Ca}^{2+}$ peaks, as well as in the frequency and duration of the peaks.

\section{$\mathrm{Ca}^{2+}$ block by $\mathrm{LaCl}_{3}$ has a small effect on $\mathrm{OS}$ differentiation in depolarized cells}

The $\mathrm{Ca}^{2+}$ blocker $\mathrm{LaCl}_{3}(500 \mu \mathrm{M})$ was administered during OS differentiation with $40 \mathrm{mM} \mathrm{K}^{+}$to determine whether the blocker alters the depolarization response. $\mathrm{LaCl}_{3}$ suppressed IBSP expression in $\mathrm{K}^{+}$-depolarized cells on day $7(p<0.0002$; Fig. 2A) and had no significant effect on day 21 calcium de-

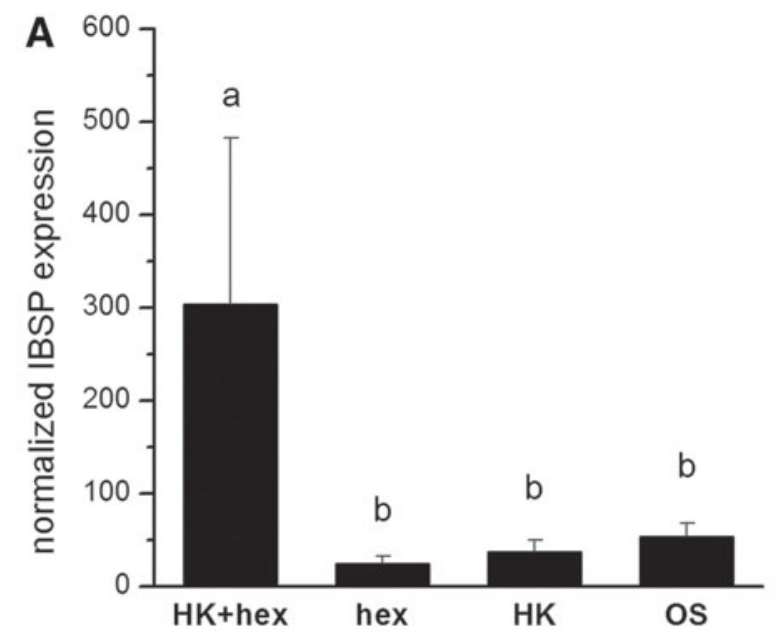

C

D
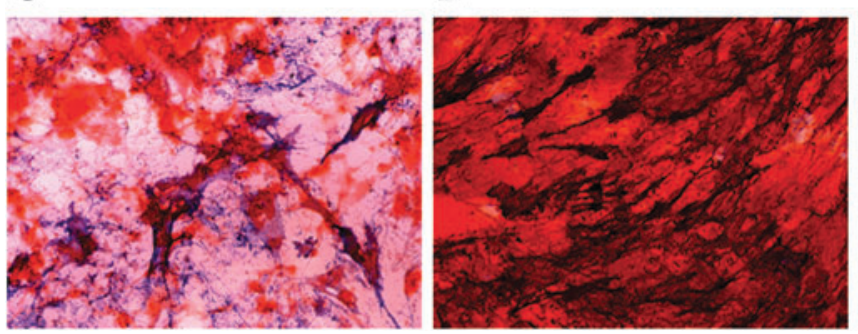

position in depolarized cells ( $p>0.05$; Fig. 2B). Alizarin Red staining on day 21 confirmed that mineral deposition was not rescued in the $\mathrm{LaCl}_{3}$-treated $\mathrm{K}^{+}$-depolarized cells (Fig. 2C-F). These results indicate that blocking $\mathrm{Ca}^{2+}$ flux does not rescue differentiation in depolarized OS cells.

\section{Treatment with hexokinase reverses depolarization's effects on OS differentiation}

Spontaneous $\mathrm{Ca}^{2+}$ oscillations in undifferentiated hMSCs are stimulated by autocrine or paracrine ATP signaling. ${ }^{36} \mathrm{We}$ investigated whether addition of hexokinase, an enzyme that consumes extracellular ATP when phosphorylating glucose, to depolarized cultures could mediate the effects of $V_{\text {mem }}$ depolarization. Addition of hexokinase reversed the differentiation suppression caused by high $\mathrm{K}^{+}$. Hexokinase rescued expression of IBSP on day 7 in $\mathrm{K}^{+}$-depolarized cells (Fig. 3A). Cells treated with high $\mathrm{K}^{+}$and hexokinase exhibited an 8.4-fold increase in IBSP compared to $\mathrm{K}^{+}$treatment alone and a 5.6-fold increase compared to untreated OS cells $(p<0.001)$. Calcium content on day 21 was also significantly elevated by hexokinase (Fig. 3B). $\mathrm{K}^{+}$-treated cells exhibited a 21.8-fold increase in calcium content with hexokinase compared to nontreated controls $(p<0.001)$, raising calcium content levels to that of nondepolarized OS cells.

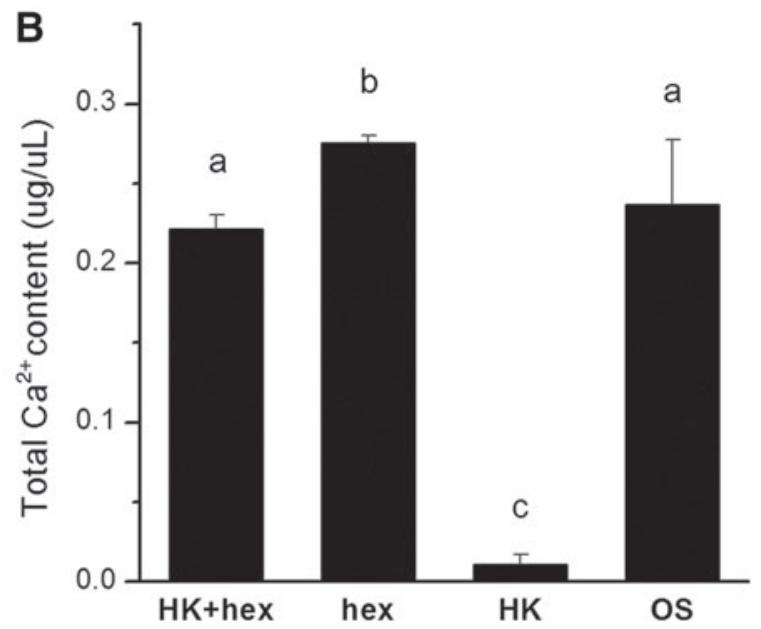

E

$\mathbf{F}$
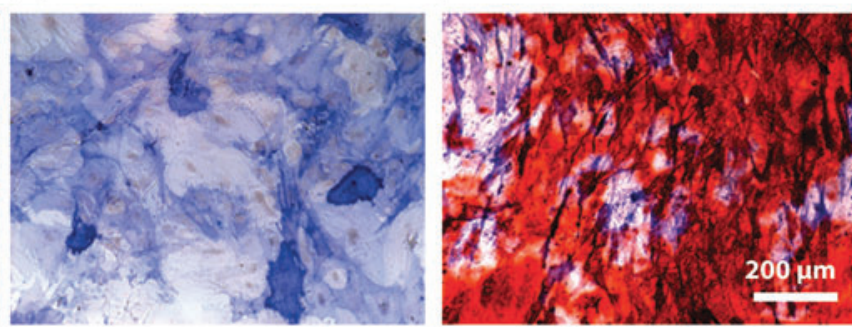

FIG. 3. Hexokinase treatment rescues OS differentiation in depolarized hMSCs. hMSCs were treated with hex (5 U/mL) to deplete the medium of ATP during OS differentiation. (A) IBSP gene expression was quantified by qPCR after 7 days of hMSC culture in OS medium with $40 \mathrm{mM} \mathrm{K} \mathrm{K}^{+}(\mathrm{HK})$ and/or hex. Data points are mean normalized expression \pm standard deviation, $n=3$. (B) Total calcium content was quantified after 21 days of hMSC culture under the same conditions. Data points represent mean calcium concentration $(\mu \mathrm{g} / \mu \mathrm{L}) \pm$ standard deviation, $n=6$. Different letters over bar graphs represent statistically different groups as determined by one-way ANOVA and the Tukey-Kramer post hoc test, $p<0.05$. (C-F) Representative images of cells stained at day 21 for ALP (blue) and calcified mineral (Alizarin Red S). Cells were grown in media supplemented with hex + HK (C), hex (D), HK (E), or in normal OS medium (F). Scale bar $=200 \mu \mathrm{m}$. ALP; alkaline phosphatase protein; hex, hexokinase; qPCR, quantitative polymerase chain reaction. 
Alizarin Red staining revealed increased mineral deposition in depolarized cells treated with hexokinase compared to depolarized cells, although not as much as OS cells (Fig. 3C-F).

Extracellular ATP may be released from cells through pannexin hemichannels. Once released, ATP may signal through purinergic receptors to affect differentiation. We used pharmacological blockers of purinergic P2 receptors and pannexin channels to determine the molecular species involved in this signaling pathway. For this study, PPADS was used as a nonselective $\mathrm{P} 2 \mathrm{X}$ and $\mathrm{P} 2 \mathrm{Y}$ receptor antagonist, TNP-ATP was used as a selective P2X receptor antagonist, and $\mathrm{CBX}$ was used as a pannexin-1 hemichannel blocker. Calcium quantification on day 21 revealed that treatment with TNP-ATP $(0.1$ and $1 \mu \mathrm{M})$ or CBX $(10 \mu \mathrm{M})$ did not significantly alter differentiation in the presence or absence of depolarization (Fig. 4). These results suggest that $\mathrm{P} 2 \mathrm{X}$ receptors and pannexin hemichannels may not play a large role in the ATP signaling pathway. PPADS (10 and $30 \mu \mathrm{M})$ markedly decreased calcium content in nondepolarized OS cells (Fig. 4), which suggests that blockade of all purinergic signaling might have a detrimental effect on differentiation. Taken together, these data indicate that hexokinase treatment blocks cellular signaling events triggered by $\mathrm{V}_{\text {mem }}$ depolarization, but that the relevant pathway does not involve ATP signaling through P2X or pannexin hemichannels.

\section{Elevation of intracellular Pi levels rescues depolarization-suppressed differentiation}

$\mathrm{Pi}$ is a major element of the ATP signaling pathway and is also critical in the function of osteoblasts. We investigated whether Pi plays a role in the response of hMSCs to depolar-

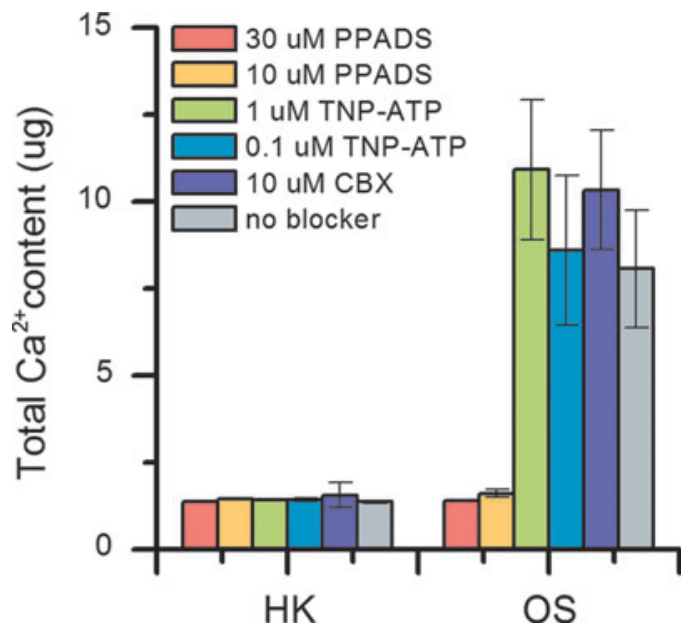

FIG. 4. Blockade of purinergic receptors or pannexin hemichannels does not reverse the effects of depolarization. Total calcium content in hMSCs was quantified after 21 days of OS differentiation under depolarized ( $\mathrm{HK}, 40 \mathrm{mM}$ high $\mathrm{K}^{+}$) or nondepolarized (OS) conditions, in the presence of 30 or $10 \mu \mathrm{M}$ PPADS, 1 or $0.1 \mu \mathrm{M}$ TNP-ATP, or $10 \mu \mathrm{M}$ CBX. Data points represent mean calcium content $(\mu \mathrm{g}) \pm$ standard deviation, $n=3$. CBX, carbenoxolone; PPADS, pyridoxalphosphate6-azophenyl-2',4'-disulfonic acid tetrasodium salt; TNP-ATP, $2^{\prime}, 3^{\prime}-O$-(2,4,6-Trinitrophenyl)adenosine-5' -triphosphate tetra(triethylammonium) salt. ization during OS differentiation. The concentration of Pi in the hMSC culture medium was elevated by $5 \mathrm{mM}$ for the first 5 days of differentiation by supplementing the differentiation medium with sodium phosphate. When Pi was added to the high $\mathrm{K}^{+}$-depolarized culture, mineral content at 21 days was increased 36.7-fold compared to HK-depolarized cells without Pi supplementation $(p<0.001)$, restoring mineral content to similar levels compared to nondepolarized cultures $(p>0.05$; Fig. 5A). When fosc was added in addition to $\mathrm{Pi}$, the rescue effect of Pi on mineral content of depolarized cultures was inhibited 2.9-fold $(p<0.001)$, but mineral levels were still 13.3-fold higher compared with depolarized cultures without $\mathrm{Pi}(p<0.006$; Fig. 5B).

We quantified the level of intracellular Pi to verify that adding extracellular Pi did indeed result in elevated intracellular Pi levels. By day 1, Pi treatment resulted in 2.1- and 1.5-fold increases in Pi levels in depolarized and nondepolarized cells, respectively (Fig. 5C; $p<0.001, p<0.02$, respectively). Despite washing out the supplemented Pi from the culture medium on day 5, intracellular Pi levels remained elevated on days 7, 14, and 21 (2.4-, 1.7-, and 2.0-fold, respectively, in depolarized cells $[p<0.001]$ and 2.6-, 2.1-, and 2.7 -fold, respectively, in nondepolarized cells $[p<0.001]$ ) (Fig. 5C).

\section{STC1 mediates the hMSC depolarization response}

A number of phosphate-regulating and phosphate-regulated genes have been implicated in osteoblast function, including secreted frizzled-related peptide 4 , ectonucleotide pyrophosphate/phosphodiesterase 1 , dentin matrix protein 1 , matrix extracellular phosphoglycoprotein with ASARM motif, high mobility group adenine-thymine-hook 1 and 2, growth arrest and DNA damage-inducible protein, Fos Proto-Oncogene-like antigen 2, and STC1. We quantified the expression of these genes but found no significant changes in expression with depolarization treatment for most genes. However, our screen identified STC1, a glycoprotein hormone involved in calcium and phosphate homeostasis, as a potential gene of interest.

We investigated whether $S T C l$ controls hMSC response to $\mathrm{V}_{\mathrm{mem}}$ depolarization during OS differentiation. STC1 expression was significantly upregulated in $\mathrm{K}^{+}$-depolarized cells compared to nondepolarized OS cells (5.7-fold), and treatment of depolarized cells with elevated Pi resulted in suppressed STC1 expression (2.17-fold lower than $\mathrm{K}^{+}$-depolarized cells) $(p<0.001$; Fig. 6A). Interestingly, the expression of SLC20A1, a sodium-phosphate cotransporter known to be regulated by $S T C 1$, was not altered by depolarization ( $p>0.05$; Fig. 6B). SLC20A1 expression does, however, increase with elevated Pi levels ( $p<0.001$; Fig. 6B), perhaps revealing that Pi can trigger another pathway unrelated to depolarization but that ultimately effects a similar differentiation response.

We conducted siRNA-mediated knockdown studies to determine whether STC1 upregulation is necessary in order for depolarization to suppress differentiation. Transfection of hMSCs with STC1 siRNA resulted in a 94.2\% knockdown of $S T C 1$ expression at $24 \mathrm{~h}$ post-transfection $(p<0.001 ;$ Fig. $6 \mathrm{C})$. STC1 knockdown persisted at day 7 of OS differentiation, with STC1-siRNA-transfected cells showing significantly lower expression than cells treated with a negative control siRNA (HK cells: 18.9-fold, OS cells: 58.1-fold, CON cells: 7.2-fold, $p<0.001$; Fig. 6D). Evaluation of OS gene expression on day 7 

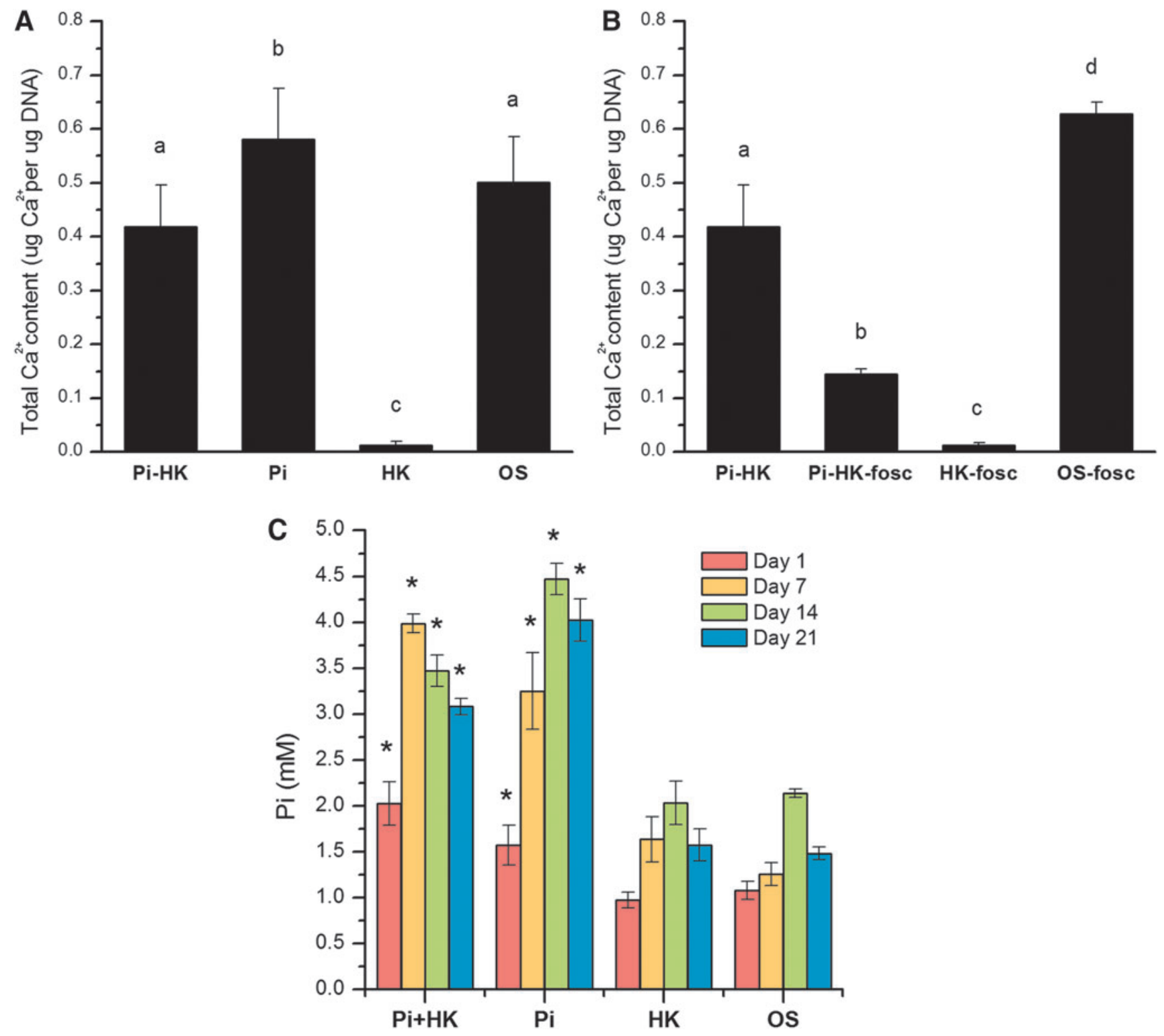

FIG. 5. Elevated Pi rescues calcification in depolarized hMSCs undergoing OS differentiation. (A) Total calcium content in hMSCs was quantified after 21 days of OS differentiation under depolarized $\left(\mathrm{HK}, 40 \mathrm{mM}\right.$ high $\mathrm{K}^{+}$) or nondepolarized (OS) conditions, with $5 \mathrm{mM}$ Pi supplementation for the first 5 days of culture. Different letters over the bars represent statistically different groups as determined by one-way ANOVA and the Tukey-Kramer post hoc test $(p<0.05)$. Groups (a), (b), and (c) were statistically different from one another, but the samples within group (a) were not statistically different from one another. (B) Total calcium content in hMSCs was quantified under the same conditions with the addition of fosc. Data points represent mean normalized calcium content $(\mu \mathrm{g} \mathrm{Ca} / \mu \mathrm{g}$ DNA $) \pm$ standard deviation, $n=3-6$. Different letters over the bars represent statistically different groups as determined by one-way ANOVA and the Tukey-Kramer post hoc test $(p<0.05)$. Groups (a), (b), (c), and (d) were statistically different from one another. (C) Intracellular Pi concentration was measured in depolarized (HK) or nondepolarized (OS) cells with or without Pi supplementation (Pi). Asterisks (*) represent significant differences relative to the corresponding depolarized or nondepolarized groups without supplemented Pi, $p<0.05$. fosc, foscarnet; $\mathrm{Pi}$, inorganic phosphate.

showed that $A L P L$ expression in depolarized cells was upregulated 3.1-fold by STC1 knockdown $(p<0.001)$, reaching similar levels as nondepolarized OS cells (Fig. 6E). IBSP expression was partially rescued by STC1 knockdown: STC1siRNA-transfected cells exhibited a 2.3-fold difference in IBSP in HK-depolarized compared to nondepolarized OS cells, versus an 18.6-fold difference in cells transfected with negative control siRNA $(p<0.001$; Fig. 6F). Interestingly, mineralization at day 21 was not rescued in STC1-knockdown cells (Fig. 6G). In fact, the ability of nondepolarized OS cells to form mineralized matrix was inhibited over 300 -fold by STC1 knockdown (Fig. 6G, H). Thus, altering STC1 expression interferes with cells' ability to accumulate calcified matrix independent of their $\mathrm{V}_{\text {mem }}$ state. 

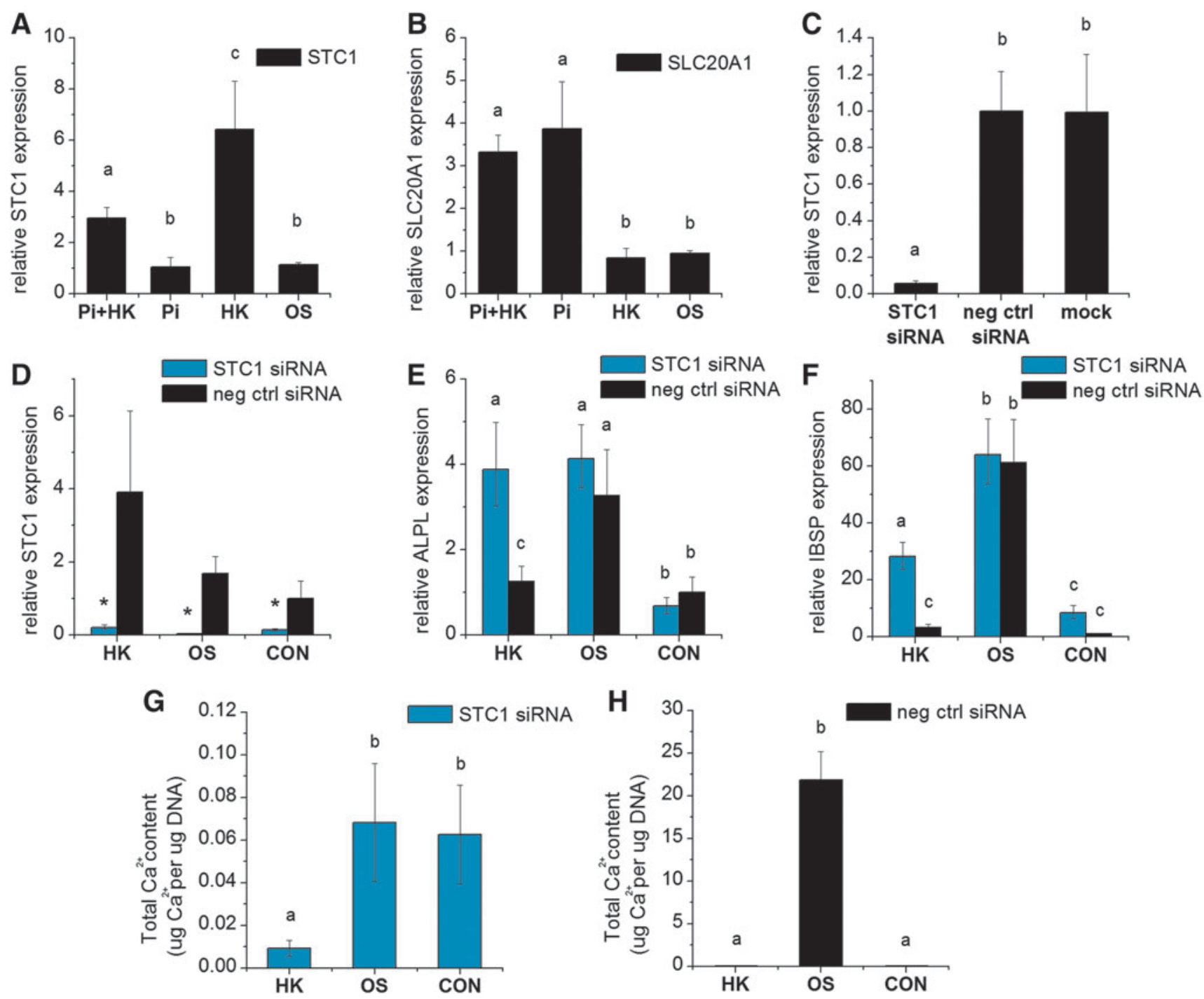

FIG. 6. STC1 gene expression is upregulated with depolarization, and STC1 knockdown rescues early OS differentiation markers, but not calcification, in depolarized hMSCs. STC1 expression (A) and sodium phosphate cotransporter SLC20A1 expression (B) were quantified on day 7 by qPCR in OS-differentiated cells cultured under depolarizing (HK) or nondepolarizing (OS) conditions with or without $0.5 \mathrm{mM}$ Pi supplementation. (C) STC1 expression was quantified $24 \mathrm{~h}$ after STC1 knockdown by siRNA. STC1-knockdown cells and negative control knockdown cells were then cultured in OS medium, OS medium with high $\mathrm{K}^{+}(\mathrm{HK})$, or control medium $(\mathrm{CON})$. On day 7, cultures were evaluated for expression of STC1 (D), ALPL (E), or IBSP (F). Data points are mean normalized expression \pm standard deviation, $n=4-6$. (G, H) On day 21 , cultures were evaluated for total calcium content. Data points represent mean normalized calcium content $(\mu \mathrm{g} \mathrm{Ca} / \mu \mathrm{g}$ DNA) \pm standard deviation, $n=4$. Different letters over bar graphs represent statistically different groups as determined by one-way ANOVA and the Tukey-Kramer post hoc test, $p<0.05$. Asterisks $(*)$ represent statistical differences between STC1-knockdown versus negative control knockdown cells, as determined by the Student's $t$-test, $p<0.05$. ALPL, alkaline phosphatase gene; STC1, Stanniocalcin 1.

\section{Discussion}

$\mathrm{Ca}^{2+}$ signaling plays an important role in osteoblast proliferation, differentiation, and chemotaxis. ${ }^{26,27}$ Several mediators of $\mathrm{Ca}^{2+}$ signaling have been shown to play important roles during osteoblast differentiation. For example, upon complexing with $\mathrm{Ca}^{2+}$, CaM binds to Smad1 and Smad 2 and regulates osteoblast differentiation through bone morphogenetic protein 2 and transforming growth factor- $\beta$ pathways. ${ }^{42}$ $\mathrm{Ca}^{2+} / \mathrm{CaM}$ also regulates $\mathrm{CaM}$ kinase II, which promotes osteoblast growth and proliferation, ${ }^{26}$ and $\mathrm{Cn}$, which plays a role in osteoblast differentiation through NFAT1-4 transcription factors. ${ }^{43-48} \mathrm{Ca}^{2+}$ influx may also influence differentiation through the Ras/Raf/MEK/MAPK signaling pathway. $\mathrm{Ca}^{2+}$ influx activates extracellular signal-regulated protein kinase (ERK), ${ }^{49-51}$ which promotes OS differentiation and suppresses AD differentiation, possibly functioning as a regulatory switch for the differentiation pathways. Taken together, these observations support a significant role for $\mathrm{Ca}^{2+}$ signaling in osteoblast differentiation.

Calcium is an important intracellular signaling molecule responsible for mediating voltage signals in excitable cells. 
We investigated the functional role of $\mathrm{Ca}^{2+}$ in transducing depolarization signals during hMSC differentiation. Depolarization was achieved by culturing the cells in OS medium containing elevated levels of $\mathrm{K}^{+}$. We have previously used this method to depolarize hMSCs and found that $40 \mathrm{mM} \mathrm{K}^{+}$ depolarized $\mathrm{V}_{\text {mem }}$ without causing nonspecific cell death. ${ }^{34,52}$ We monitored intracellular $\mathrm{Ca}^{2+}$ levels before and after addition of high $\mathrm{K}^{+}$and found that nondepolarized hMSCs exhibited spontaneous $\mathrm{Ca}^{2+}$ oscillations and that depolarization caused small changes in the dynamics of these oscillations. To determine whether these depolarization-induced changes in $\mathrm{Ca}^{2+}$ were functionally relevant to differentiation, the nonspecific $\mathrm{Ca}^{2+}$ blocker $\mathrm{LaCl}_{3}$ was administered with $40 \mathrm{mM} \mathrm{K}^{+}$during OS differentiation. Neither mineralization nor IBSP expression was rescued by $\mathrm{LaCl}_{3}$, suggesting that changes in $\mathrm{Ca}^{2+}$ flux dynamics are not major causative factors for the suppression of hMSC differentiation observed with depolarization. It was noted that $\mathrm{LaCl}_{3}$ treatment during depolarization in fact suppressed day 7 IBSP expression to levels even lower compared with the nontreated depolarized cells, which suggests that altering $\mathrm{Ca}^{2+}$ flux did impact early OS gene expression. However, this effect did not persist through day 21 , when calcified mineral was quantified, which suggests that the effect was transient.

The involvement of extracellular ATP in $\mathrm{Ca}^{2+}$-mediated signaling was then investigated, as autocrine ATP signaling has been reported to stimulate $\mathrm{Ca}^{2+}$ oscillations in undifferentiated hMSCs. ${ }^{36}$ ATP was depleted from hMSC medium with hexokinase in the presence of high $\mathrm{K}^{+}$, resulting in the rescue of OS gene expression, calcium content, and mineralization in depolarized cells. To determine the specific mechanistic basis of this hMSC response, we probed several known ATP signaling pathways. Nonspecific inhibition of purinergic signaling disrupted the mineralization capacity of cells regardless of $\mathrm{V}_{\text {mem }}$ state; thus it is difficult to speculate on the specific role of purinergic signaling in the context of depolarization. Blockade of ATP signaling through $\mathrm{P} 2 \mathrm{X}$ receptors or blockade of ATP release from pannexin hemichannels did not achieve the same effect as addition of hexokinase, suggesting that another aspect of the ATP pathway is involved.

$\mathrm{Pi}$, which is released during ATP consumption and which is a key regulator of bone function, may be responsible for the observed rescuing effect of ATP depletion. Pi is hypothesized to function as a signaling molecule in osteoblasts, functioning to coordinate protein function and gene expression necessary for mineralization. ${ }^{28-31,33}$ Osteoblast-relevant signaling pathways known to be regulated by $\mathrm{Pi}$ include extracellular signalregulated kinase $1 / 2$ (ERK 1/2), protein kinase C, osteopontin, and Runx $2 .^{28,30}$ In our study, supplementation of depolarized cultures with Pi resulted in the rescued expression of mature OS markers, suggesting a role for $\mathrm{Pi}$ in the response of hMSCs to $\mathrm{V}_{\text {mem }}$ levels. One route of Pi flux across the cell membrane is through the type III sodium-phosphate cotransporter PiT1 (SLC20A1). SLC20A1 gene expression, while reported in the literature to respond to $\mathrm{Pi}$ levels and to regulate osteoblast mineralization, ${ }^{31,32}$ was not found to be responsive to $V_{\text {mem }}$ levels in our study. However, this does not rule out the possibility that SLC20A1 activity, rather than expression, may play an important role.

Our study revealed that $S T C 1$ expression levels were responsive to depolarization. STC1 is the mammalian homolog of a fish calcium/phosphate handling protein and is hypoth- esized to regulate calcium and phosphate homeostasis in mammals as it does in fish. ${ }^{53}$ It is reported to stimulate bone mineralization by increasing phosphate uptake through the PiT1 transporter. ${ }^{53}$ STC1 may play an autocrine or paracrine role during bone development, and STC1 overexpression is reported to decrease bone formation rate. ${ }^{54,55}$ In our study, STC1 expression was significantly elevated in depolarized cells, and this overexpression was inhibited by treatment with elevated Pi. STC1 upregulation was functionally necessary for the hMSC depolarization response, as STC1 knockdown resulted in restored OS gene expression. However, likely due to the critical role of STC1 in calcium and phosphate homeostasis, STC1-knockdown cells were unable to produce mineral at later stages of differentiation; thus, any rescue effects could not be seen at this stage. It is possible that a less effective STC1 knockdown (as opposed to the $94.2 \%$ knockdown seen in this study) could facilitate a rescue experiment that does not completely interfere with the cell's endogenous ability to produce mineral and could shed light on whether STC1 also mediates the late-stage effects of depolarization.

In conclusion, this study examined the role of $\mathrm{Ca}^{2+}$ and $\mathrm{Pi}$, two critical components of the bone mineral matrix, in the response of hMSC OS differentiation to $\mathrm{V}_{\text {mem }}$ depolarization. Although $\mathrm{Ca}^{2+}$ is an important signaling molecule in OS cells and is also a mediator of voltage signals in excitable cells such as neurons and muscle, we found that $\mathrm{Ca}^{2+}$ did not play a large role in the response of hMSCs to $\mathrm{V}_{\text {mem }}$ depolarization

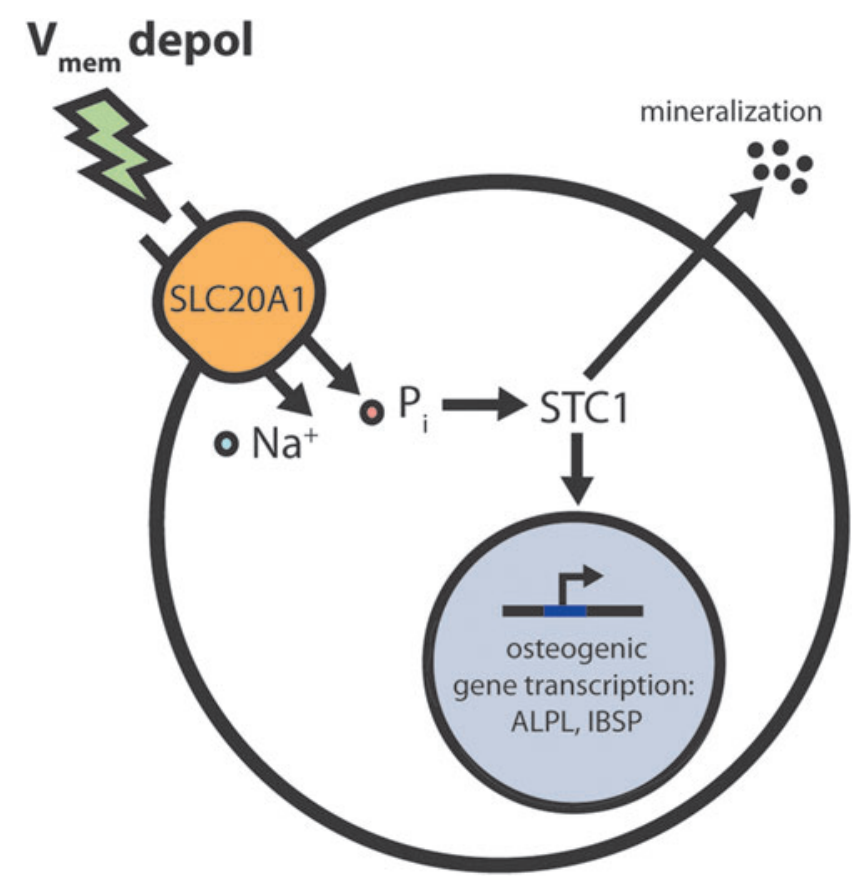

FIG. 7. Schematic depicting proposed phosphate- and STC1-related interactions involved in hMSC depolarization during OS differentiation. $\mathrm{V}_{\text {mem }}$ depol may alter $\mathrm{Na}^{+}$and $\mathrm{Pi}$ transport across the cell membrane through the $\mathrm{Na}^{+}-$ dependent Pi cotransporter SLC20A1. Pi levels, in turn, may alter intracellular STC1 expression. STC1 regulates the expression of OS genes such as $A L P L$ and IBSP and also critically regulates late-stage mineralization. $\mathrm{V}_{\text {mem }}$ depol, membrane potential depolarization. 
by high $\mathrm{K}^{+}$. High $\mathrm{K}^{+}$treatment induced only small changes in spontaneous $\mathrm{Ca}^{2+}$ oscillations in the cells, and blockade of $\mathrm{Ca}^{2+}$ flux across the cell membrane did not reverse the suppression of differentiation caused by high $\mathrm{K}^{+}$. In contrast, treatment with elevated $\mathrm{Pi}$ did rescue differentiation under depolarizing conditions, implicating a role for Pi signaling in response to induced voltage changes. The expression of $\mathrm{STC} 1$, a protein involved in $\mathrm{Ca}^{2+}$ and $\mathrm{Pi}$ homeostasis, was upregulated by depolarization, and artificial suppression of STC1 expression by siRNA rescued cells from suppressed OS gene expression. These results suggest that the Pi signaling pathway, and STC1 in particular, mediates hMSC response to $\mathrm{V}_{\text {mem }}$ depolarization during OS differentiation (Fig. 7). Further mechanistic work in this and other systems is critical for understanding stem cell response to voltage cues and suggests the need to test $\mathrm{Pi} / \mathrm{STC} 1$ signaling in vivo, where bioelectric changes are important regulators of pattern formation. ${ }^{56}$ Such an understanding will equip us with a greater level of control in the modulation of tissue development and regeneration in vitro and in vivo, with great potential to advance regenerative medicine efforts and stem cell therapies.

\section{Acknowledgments}

The authors thank the NIH for support through the Tissue Engineering Resource Center (P41 EB002520), R01 AR005593, and R01 AR061988; the G. Harold and Leila Y. Mathers Charitable Foundation; and the W.M. Keck Foundation.

\section{Author Disclosure Statement}

No competing financial interests exist.

\section{References}

1. Pai V, Levin M. Bioelectric controls of stem cell function. In Calegari, F., and Waskow, C. eds. Stem Cells. CRC Press, Boca Raton, Florida: 2013:106-148.

2. Konig S, Hinard V, Arnaudeau S, et al. Membrane hyperpolarization triggers myogenin and myocyte enhancer factor-2 expression during human myoblast differentiation. J Biol Chem 2004;279:28187-28196.

3. Liu JH, Bijlenga P, Fischer-Lougheed J, et al. Role of an inward rectifier $\mathrm{K}+$ current and of hyperpolarization in human myoblast fusion. J Physiol 1998;510:467-476.

4. Fischer-Lougheed J, Liu JH, Espinos E, et al. Human myoblast fusion requires expression of functional inward rectifier Kir2.1 channels. J Cell Biol 2001;153:677-685.

5. Hinard V, Belin D, Konig S, et al. Initiation of human myoblast differentiation via dephosphorylation of Kir2.1 $\mathrm{K}+$ channels at tyrosine 242. Development 2008;135:859867.

6. Konig S, Beguet A, Bader $\mathrm{CR}$, et al. The calcineurin pathway links hyperpolarization (Kir2.1)-induced $\mathrm{Ca} 2+$ signals to human myoblast differentiation and fusion. Development 2006;133:3107-3114.

7. van Vliet $\mathrm{P}$, de Boer TP, van der Heyden MAG, et al. Hyperpolarization induces differentiation in human cardiomyocyte progenitor cells. Stem Cell Rev Rep 2010;6:178185.

8. Kleger A, Seufferlein T, Malan D, et al. Modulation of calcium-activated potassium channels induces cardiogenesis of pluripotent stem cells and enrichment of pacemakerlike cells. Circulation 2010;122:1823-1836.
9. Sato M, Suzuki K, Yamazaki H, et al. A pivotal role of calcineurin signaling in development and maturation of postnatal cerebellar granule cells. Proc Natl Acad Sci U S A 2005;102:5874-5879.

10. Ng SY, Chin CH, Lau YT, et al. Role of voltage-gated potassium channels in the fate determination of embryonic stem cells. J Cell Physiol 2010;224:165-177.

11. Levin M, Stevenson CG. Regulation of cell behavior and tissue patterning by bioelectrical signals: Challenges and opportunities for biomedical engineering. Annu Rev Biomed Eng 2012;14:295-323.

12. Tseng A, Levin M. Cracking the bioelectric code: Probing endogenous ionic controls of pattern formation. Commun Integr Biol 2013;6:1-8.

13. Cherubini A, Hofmann G, Pillozzi S, et al. Human ether-ago-go-related gene 1 channels are physically linked to beta1 integrins and modulate adhesion-dependent signaling. Mol Biol Cell 2005;16:2972-2983.

14. Arcangeli A, Becchetti A. Complex functional interaction between integrin receptors and ion channels. Trends Cell Biol 2006;16:631-639.

15. Liu J, DeYoung SM, Zhang M, et al. Changes in integrin expression during adipocyte differentiation. Cell Metab 2005; 2:165-177.

16. Meyers VE, Zayzafoon M, Gonda SR, et al. Modeled microgravity disrupts collagen I/integrin signaling during osteoblastic differentiation of human mesenchymal stem cells. J Cell Biochem 2004;93:697-707.

17. Nesti LJ, Caterson EJ, Wang M, et al. TGF- $\beta 1$ calcium signaling increases $\alpha 5$ integrin expression in osteoblasts. J Orthopaedic Res 2002;20:1042-1049.

18. Iwasaki H, Murata Y, Kim Y, et al. A voltage-sensing phosphatase, Ci-VSP, which shares sequence identity with PTEN, dephosphorylates phosphatidylinositol 4,5-bisphosphate. Proc Natl Acad Sci U S A 2008;105:7970-7975.

19. Murata Y, Iwasaki H, Sasaki M, et al. Phosphoinositide phosphatase activity coupled to an intrinsic voltage sensor. Nature 2005;435:1239-1243.

20. Murata Y, Okamura Y. Depolarization activates the phosphoinositide phosphatase Ci-VSP, as detected in Xenopus oocytes coexpressing sensors of PIP2. J Physiol 2007;583: 875-889.

21. Levin M, Buznikov GA, Lauder JM. Of minds and embryos: Left-right asymmetry and the serotonergic controls of pre-neural morphogenesis. Dev Neurosci 2006;28:171185.

22. Slusarski DC, Pelegri F. Calcium signaling in vertebrate embryonic patterning and morphogenesis. Dev Biol 2007; 307:1-13.

23. Webb SE, Miller AL. Calcium signalling during zebrafish embryonic development. Bioessays 2000;22:113-123.

24. Jaffe LF. Organization of early development by calcium patterns. Bioessays 1999;21:657-667.

25. Jaffe L. Calcium waves and development. In Calcium Waves, Gradients and Oscillations. Gregory R. Bock, Kate Ackrill eds. Chichester: CIBA Foundation, 1995:4-17.

26. Zayzafoon M, Fulzele K, McDonald JM. Calmodulin and calmodulin-dependent kinase II $\alpha$ regulate osteoblast differentiation by controlling c-fos expression. J Biol Chem 2005;280:7049-7059.

27. Silver IA, Murrills RJ, Etherington DJ. Microelectrode studies on the acid microenvironment beneath adherent macrophages and osteoclasts. Exp Cell Res 1988;175:266276. 
28. Khoshniat S, Bourgine A, Julien M, et al. The emergence of phosphate as a specific signaling molecule in bone and other cell types in mammals. Cell Mol Life Sci 2011;68: 205-218.

29. Beck GR, Jr. Inorganic phosphate as a signaling molecule in osteoblast differentiation. J Cell Biochem 2003;90:234 243.

30. Beck GR, Jr, Knecht N. Osteopontin regulation by inorganic phosphate is ERK1/2-, protein kinase C-, and proteasomedependent. J Biol Chem 2003;278:41921-41929.

31. Yoshiko Y, Candeliere GA, Maeda N, et al. Osteoblast autonomous $\mathrm{Pi}$ regulation via Pit1 plays a role in bone mineralization. Mol Cell Biol 2007;27:4465-4474.

32. Miyamoto K, Haito-Sugino S, Kuwahara S, et al. Sodiumdependent phosphate cotransporters: Lessons from gene knockout and mutation studies. J Pharm Sci 2011;100: 3719-3730.

33. Zoidis E, Ghirlanda-Keller C, Gosteli-Peter M, et al. Regulation of phosphate $(\mathrm{Pi})$ transport and NaPi-III transporter (Pit-1) mRNA in rat osteoblasts. J Endocrinol 2004;181: 531-540.

34. Sundelacruz S, Levin M, Kaplan DL. Membrane potential controls adipogenic and osteogenic differentiation of mesenchymal stem cells. PLoS ONE 2008;3:e3737.

35. Coppi E, Pugliese AM, Urbani S, et al. ATP modulates cell proliferation and elicits two different electrophysiological responses in human mesenchymal stem cells. Stem Cells 2007;25:1840-1849.

36. Kawano S, Otsu K, Kuruma A, et al. ATP autocrine/paracrine signaling induces calcium oscillations and NFAT activation in human mesenchymal stem cells. Cell Calcium 2006;39:313-324.

37. Lambrecht G. Agonists and antagonists acting at P2X receptors: Selectivity profiles and functional implications. Naunyn Schmiedebergs Arch Pharmacol 2000;362:340350.

38. Von Kugelgen I, Wetter A. Molecular pharmacology of P2Y-receptors. Naunyn Schmiedebergs Arch Pharmacol 2000;362:310-323.

39. Beck GR, Jr, Zerler B, Moran E. Phosphate is a specific signal for induction of osteopontin gene expression. Proc Natl Acad Sci U S A 2000;97:8352-8357.

40. Goldman DE. Potential, impedance, and rectification in membranes. J Gen Physiol 1943;27:37-60.

41. Hodgkin AL, Katz B. The effect of sodium ions on the electrical activity of giant axon of the squid. J Physiol 1949; 108:37-77.

42. Scherer A, Graff JM. Calmodulin differentially modulates Smad1 and Smad2 signaling. J Biol Chem 2000;275: 41430-41438.

43. Bassel-Duby R, Olson EN. Role of calcineurin in striated muscle: Development, adaptation, and disease. Biochem Biophys Res Commun 2003;311:1133-1141.
44. Crabtree GR, Olson EN. NFAT signaling: Choreographing the social lives of cells. Cell 2002;109 Suppl:S67-S79.

45. Parsons SA, Milla DP, Wilkins BJ, et al. Genetic loss of calcineurin blocks mechanical overload-induced skeletal muscle fiber type switching but not hypertrophy. J Biol Chem 2004;279:26192-26200.

46. McCabe LR, Banerjee C, Kundu R, et al. Developmental expression and activities of specific Fos and Jun proteins are functionally related to osteoblast maturation: Role of Fra-2 and Jun D during differentiation. Endocrinology 1996;137:4398-4408.

47. Yeo A, McDonald JM, Zayzafoon M. NFATc1: a novel anabolic therapeutic target for osteoporosis. Ann NY Academy Sci, 2006;1068:564-567.

48. Neal JW, Clipstone NA. Calcineurin mediates the calciumdependent inhibition of adipocyte differentiation in 3T3-L1 cells. J Biol Chem 2002;277:49776-49781.

49. Lewis TS, Shapiro PS, Ahn NG. Signal transduction through MAP kinase cascades. Adv Cancer Res 1998;74:137-139.

50. Marshall C. How do small GTPase signal transduction pathways regulate cell cycle entry? Curr Opin Cell Biol 1999;11:732-736.

51. Robinson MJ, Cobb MH. Mitogen-activated protein kinase pathways. Curr Opin Cell Biol 1997;9:180-186.

52. Sundelacruz S, Levin M, Kaplan DL. Depolarization alters phenotype, maintains plasticity of predifferentiated mesenchymal stem cells. Tissue Eng Part A 2013;19:1889-1908.

53. Yoshiko Y, Maeda N, Aubin JE. Stanniocalcin 1 stimulates osteoblast differentiation in rat calvaria cell cultures. Endocrinology 2003;144:4134-4143.

54. Johnston J, Ramos-Valdes Y, Stanton LA, et al. Human stanniocalcin-1 or -2 expressed in mice reduces bone size and severely inhibits cranial intramembranous bone growth. Transgenic Res 2010;19:1017-1039.

55. Yoshiko Y, Aubin JE, Maeda N. Stanniocalcin 1 (STC1) protein and mRNA are developmentally regulated during embryonic mouse osteogenesis: The potential of stc1 as an autocrine/paracrine factor for osteoblast development and bone formation. J Histochem Cytochem 2002;50:483-492.

56. Levin M. Molecular bioelectricity: How endogenous voltage potentials control cell behavior and instruct pattern regulation in vivo. Mol Biol Cell 2014;25:3835-3850.

Address correspondence to: David L. Kaplan, PhD Department of Biomedical Engineering Tufts University 4 Colby Street Medford, MA 02155.

Email: david.kaplan@tufts.edu 